\title{
Field Assessment and Specification Review for Roller-Integrated Compaction Monitoring Technologies
}

\author{
David J. White, Pavana K. R. Vennapusa, and Heath H. Gieselman \\ Department of Civil, Construction, and Environmental Engineering, Center for Earthworks Engineering Research, \\ Iowa State University of Science and Technology, Ames, IA 50011-8664, USA \\ Correspondence should be addressed to Pavana K. R. Vennapusa, pavanv@iastate.edu
}

Received 1 May 2011; Accepted 31 July 2011

Academic Editor: Sai K. Vanapalli

Copyright ( 2011 David J. White et al. This is an open access article distributed under the Creative Commons Attribution License, which permits unrestricted use, distribution, and reproduction in any medium, provided the original work is properly cited.

Roller-integrated compaction monitoring (RICM) technologies provide virtually 100-percent coverage of compacted areas with real-time display of the compaction measurement values. Although a few countries have developed quality control (QC) and quality assurance (QA) specifications, broader implementation of these technologies into earthwork construction operations still requires a thorough understanding of relationships between RICM values and traditional in situ point test measurements. The purpose of this paper is to provide: (a) an overview of two technologies, namely, compaction meter value (CMV) and machine drive power (MDP); (b) a comprehensive review of field assessment studies, (c) an overview of factors influencing statistical correlations, (d) modeling for visualization and characterization of spatial nonuniformity; and (e) a brief review of the current specifications.

\section{Introduction}

Roller-integrated compaction monitoring (RICM) technologies refer to sensor measurements integrated into compaction machines. Work in this area was initiated over 30 years ago in Europe for smooth drum rollers compacting granular soils and involved instrumenting the roller with an accelerometer and calculating the ratio of the fundamental frequency to the first harmonic $[1,2]$. Modern sensor technologies, computers, and global positioning system (GPS) technologies now make it possible to collect, transmit, and visualize a variety of RICM measurements in real time. As a quality assessment tool for compaction of earth materials, these technologies offer tremendous potential for field controlling the construction process to meet performance quality standards. Recent efforts in the United States (US) have focused attention on how RICM technologies can be used in road building [3-5] and relating selected RICM parameters to mechanistic pavement design values.

Several manufactures currently offer RICM technologies on smooth drum vibratory roller configurations for compaction of granular materials and asphalt, and nonvibratory roller configurations for compaction of cohesive materials.
The current technologies calculate: (1) an index value based on a ratio of selected frequency harmonics for a set time interval for vibratory compaction $[1,2],(2)$ ground stiffness or dynamic elastic modulus based on a drumground interaction model for vibratory compaction [6-8], or (3) a measurement of rolling resistance calculated from machine drive power (MDP) for vibratory and nonvibratory compaction [9]. When the accelerometer-based measurement system provides automatic feedback control for roller vibration amplitude and/or frequency and/or roller speed control, it is referred to as "intelligent" compaction and offers the advantage of reducing the potential for drum "bouncing". The MDP approach has the advantage of working in both vibratory and static modes [9] and has its origin in the discipline of terramechanics. Recent finding from the Mars Exploratory Rover (MER) mission demonstrated that the MDP approach can be applied to determine Martian regolith cohesion and friction angle by monitoring the electromechanical work expended [10]. Future RICM technologies may provide information on soil mineralogy and moisture content but are currently only a subject of research.

Regardless of the technology, by making the compaction machine a measuring device and insuring that compaction 
requirements are met during construction, the compaction process can be better controlled to improve quality, reduce rework, maximize productivity, and minimize costs [11]. Recent advancements with global positioning systems (GPS) add a significant benefit with real time spatial viewing of the RICM values. Some of these technologies have recently been implemented on full-scale pilot earthwork and asphalt construction projects in the US [12-18], and its use is anticipated to increase in the upcoming years. Effective implementation of this technology needs proper understanding of the relationships between RICM values and traditional in situ point test compaction measurements (e.g., static or dynamic plate load test modulus, density, etc.). This builds confidence in the technology and provides insight into the key parameters affecting the machine measurement values.

The purpose of this paper is to provide: (a) an overview of two technologies-compaction meter value (CMV) and machine drive power (MDP); (b) a summary of field evaluation studies, (c) an overview of factors influencing the statistical correlations, (d) modeling for visualization and characterization of spatial nonuniformity, and (e) a brief review of the current specifications.

\section{Overview of CMV and MDP Technologies}

Compaction meter value (CMV) is a dimensionless compaction parameter developed by Geodynamik that depends on roller dimensions, (i.e., drum diameter and weight) and roller operation parameters (e.g., frequency, amplitude, speed) and is determined using the dynamic roller response $[19,20]$. CMV is calculated using (1), where $C$ is a constant (used as 300 for the results presented in this paper), and $A_{2 \Omega}=$ the acceleration of the first harmonic component of the vibration, $A_{\Omega}=$ the acceleration of the fundamental component of the vibration [8]:

$$
\mathrm{CMV}=C \cdot \frac{A_{2 \Omega}}{A_{\Omega}} .
$$

According to Geodynamik [21], CMV at a given point indicates an average value over an area whose width equals the width of the drum and length equal to the distance the roller travels in 0.5 seconds. At least two manufactures have used the CMV technology as part of their RICM systems (Figure 1). The Geodynamik system also measures the resonant meter value (RMV) which provides an indication of the drum behavior (continuous contact, partial uplift, double jump, rocking motion, and chaotic motion). RMV is not discussed in detail here, but it is important to note that the drum behavior affects the CMV measurements [6] and therefore CMV must be interpreted in conjunction with RMV [22].

Machine drive power (MDP) technology relates the mechanical performance of the roller during compaction to the properties of the compacted soil. The use of MDP as a measure of soil compaction is a concept originated from study of vehicle-terrain interaction [23]. The basic premise of determining soil compaction from changes in equipment response is that the efficiency of mechanical motion pertains not only to the mechanical system but also to the physical properties of the material being compacted. More detailed background information on the MDP system is provided in [9]. The basic formula for MDP is

$$
\mathrm{MDP}=P_{g}-W V\left(\sin \alpha+\frac{a}{g}\right)-(m V+b),
$$

where $P_{g}=$ gross power needed to move the machine $(\mathrm{kJ} / \mathrm{s})$, $W=$ roller weight $(\mathrm{kN}), a=$ machine acceleration $\left(\mathrm{m} / \mathrm{s}^{2}\right)$, $g=$ acceleration of gravity $\left(\mathrm{m} / \mathrm{s}^{2}\right), \alpha=$ slope angle (roller pitch from a sensor), $V=$ roller velocity $(\mathrm{m} / \mathrm{s})$, and $m(\mathrm{~kJ} / \mathrm{m})$ and $b(\mathrm{~kJ} / \mathrm{s})=$ machine internal loss coefficients specific to a particular machine [9]. The second and third terms of (2) account for the machine power associated with sloping grade and internal machine loss, respectively. MDP is a relative value referencing the material properties of the calibration surface, which is generally a hard compacted surface (MDP = $0 \mathrm{~kJ} / \mathrm{s}$ ). Positive MDP values therefore indicate material that is less compact than the calibration surface, while negative MDP values would indicate material that is more compacted than the calibration surface (i.e., less roller drum sinkage). In some recent field studies [13], the MDP output value has been scaled to $\mathrm{MDP}_{80}$ or $\mathrm{MDP}_{40}$ depending on the modified settings which are recalculated to range between 1 and 150 using (3) and (4), respectively,

$$
\begin{aligned}
& \mathrm{MDP}_{80}=150-1.37(\mathrm{MDP}), \\
& \mathrm{MDP}_{40}=150-2.75 \text { (MDP). }
\end{aligned}
$$

For the $\mathrm{MDP}_{80}$ calculation, the calibration surface with $\mathrm{MDP}=0 \mathrm{~kJ} / \mathrm{s}$ is scaled to $\mathrm{MDP}_{80}=150$, and a soft surface with $\mathrm{MDP}=108.47 \mathrm{~kJ} / \mathrm{s}(80000 \mathrm{lb}-\mathrm{ft} / \mathrm{s})$ is scaled to $\mathrm{MDP}_{80}=$ 1. For the $\mathrm{MDP}_{40}$ calculation, the calibration surface with $\mathrm{MDP}=0 \mathrm{~kJ} / \mathrm{s}$ is scaled to $\mathrm{MDP}_{40}=150$ and a soft surface with $\mathrm{MDP}=54.23 \mathrm{~kJ} / \mathrm{s}(40000 \mathrm{lb}-\mathrm{ft} / \mathrm{s})$ is scaled to $\mathrm{MDP}_{40}=$ 1.

Effective use of RICM technologies is aided by the integration of GPS position information and an on-board computer monitor (Figure 1) which displays the roller location, machine measurement values (i.e., CMV or MDP), vibration amplitude and frequency, and roller speed. Thus, the technology enables a roller operator to make judgments regarding the condition of the compacted fill material in real time. If real-time kinematic (RTK) GPS systems are used, those systems reportedly have position accuracies of about $\pm 10 \mathrm{~mm}$ in the horizontal plane and $\pm 20 \mathrm{~mm}$ in the vertical plane [24].

\section{Field Evaluation of CMV and MDP Technologies}

Field evaluation studies beginning in about 1980 have documented correlations between RICM measurements and various traditionally used point measurements. A summary of key findings from these different studies, types of rollers used, and materials tested is provided in Table 1. A variety of QC/QA measurements have been used in the documented correlation studies, which include: 


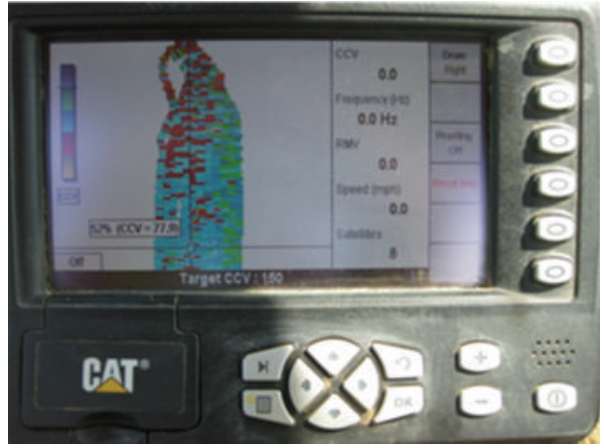

(a)

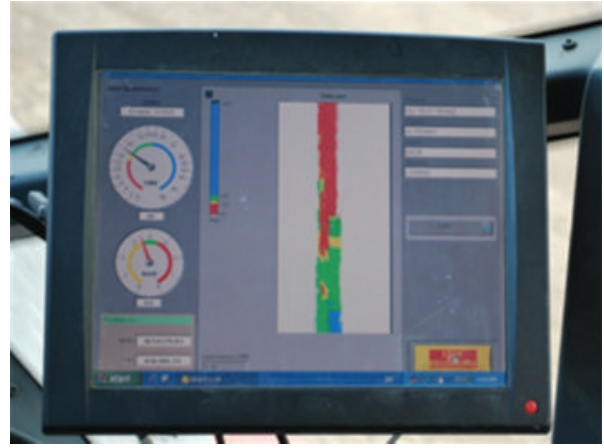

(b)

Figure 1: Photographs of on-board display units by Caterpillar (a) and Dynapac (b).

(a) nuclear gauge (NG), electrical soil density gauge (SDG), water balloon method, sand cone replacement method, radio isotope method, "undisturbed" shelby tube sampling, and drive core samples to determine moisture content and dry unit weight,

(b) light weight deflectometer (LWD), soil stiffness gauge (SSG), static plate load test (PLT), falling weight deflectometer (FWD), Briaud compaction (BCD), dynamic seismic pavement analyzer (D-SPA), and Clegg hammer to determine stiffness or modulus,

(c) dynamic cone penetrometer (DCP), cone penetration testing (CPT), "undisturbed" shelby tube sampling, and rut depth measurements under heavy test rolling to determine shear strength or California bearing ratio $(\mathrm{CBR})$.

Most of the field studies involved constructing and testing controlled field test sections for research purposes and correlation development, while a few studies were conducted on full-scale earthwork construction projects where RICM was implemented as part of the project specifications [12, 13].

Based on the findings from a comprehensive correlation study conducted on 17 different soil types from multiple project sites as part of the National Cooperative Highway Research Program (NCHRP) 21-09 project [25], the factors that commonly affect the correlations are as follows:

(1) heterogeneity in underlying layer support conditions,

(2) high moisture content variation,

(3) narrow range of measurements,

(4) machine operation setting variation (e.g., amplitude, frequency, speed, and roller "jumping"),

(5) nonuniform drum/soil contact conditions,

(6) uncertainty in spatial pairing of point measurements and roller MVs,

(7) limited number of measurements,

(8) not enough information to interpret the results,

(9) intrinsic measurement errors associated with the RICM and in situ point measurements.
In general, results from controlled field studies indicate that statistically valid simple linear or simple nonlinear correlations between RICM values and compaction layer point-MVs (e.g., modulus or density) are possible when the compaction layer is underlain by a relatively homogenous and stiff/stable supporting layer. For example, Figure 2 presents simple linear regression relationships between CMV and in situ LWD modulus and dry density point-MVs obtained from a calibration test strip with plan dimensions of $30 \mathrm{~m} \times 2 \mathrm{~m}$. The test strip consisted of silty sand with gravel base material underlain by a very stiff fly ash stabilized subgrade layer. For this case, correlations between CMV and both LWD modulus and dry density measurements showed $R^{2}>0.8$.

On the contrary, many field studies summarized in Table 1 indicate that modulus- or stiffness-based measurements (i.e., determined by FWD, LWD, PLT, etc.) generally correlate better with the RICM measurements than compaction layer dry unit weight or CBR measurements. This is illustrated in Figures 3 and 4. Data presented in Figure 3 was obtained from several calibration and production test areas with lean clay subgrade, recycled asphalt subbase, recycled concrete base, and crushed limestone base materials compacted with a vibratory smooth drum roller. Data presented in Figure 4 was obtained from several calibration and production test areas with lean clay subgrade compacted using a nonvibratory padfoot roller. CBR measurements presented herein are obtained from DCP tests using empirical correlations between DCP index values and CBR [38]. Figures 3 and 4 clearly indicate that CMV correlates better with LWD modulus point-MVs compared to dry unit weight or CBR point-MVs. One of the primary reasons for this is that modulus measurements represent a composite layered soil response under an applied load which simulates vibratory drum-ground interaction. The density and CBR measurements are average measurements of the compaction layer and do not directly represent a composite layered soil response under loading. Although DCP-CBR measurements did not correlate well in the two cases presented in Figures 3 and 4 , many field studies $[13,25,34]$ have indicated that DCP tests are effective in detecting deeper "weak" areas (at depths $>300 \mathrm{~mm}$ ) that are commonly identified by 


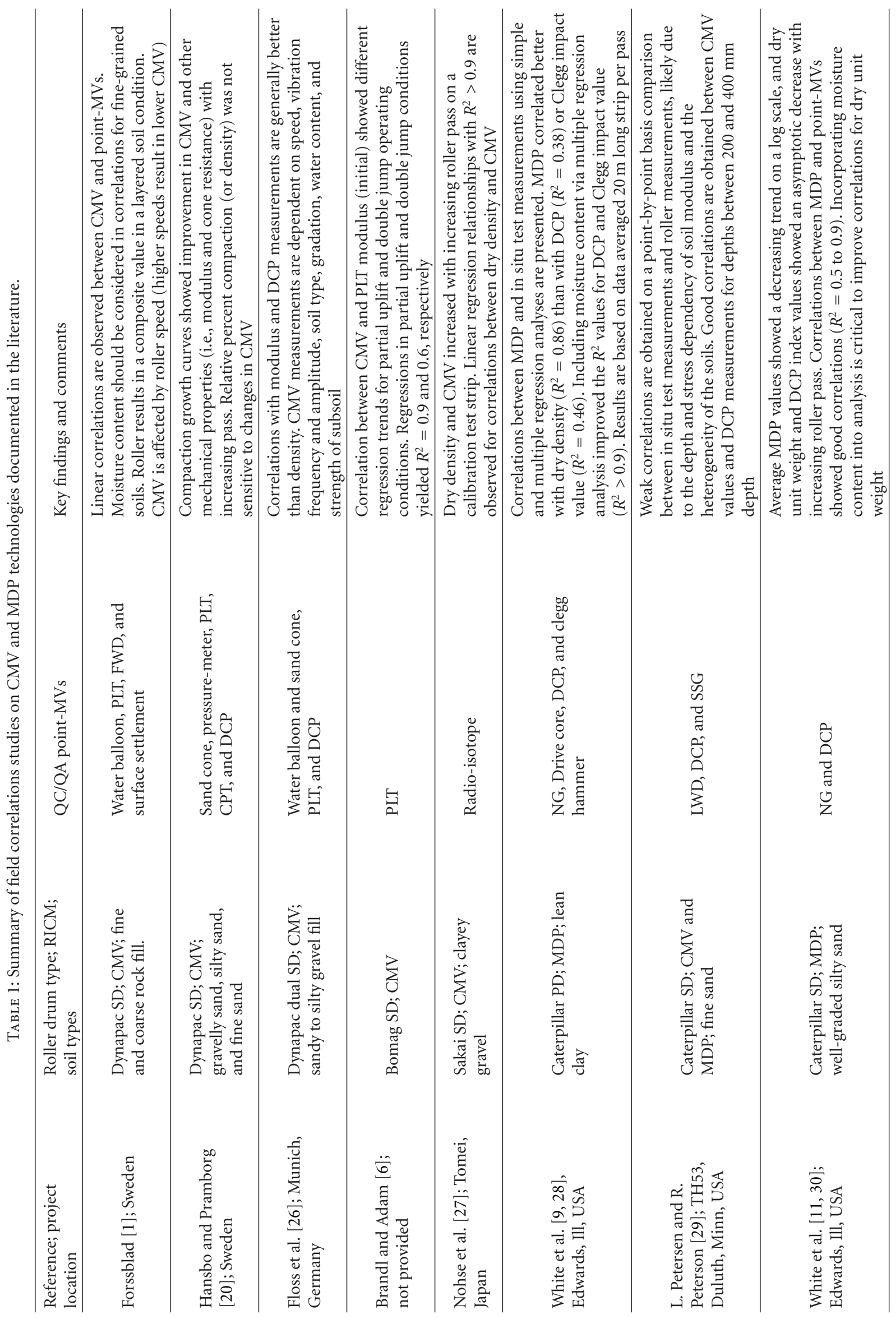




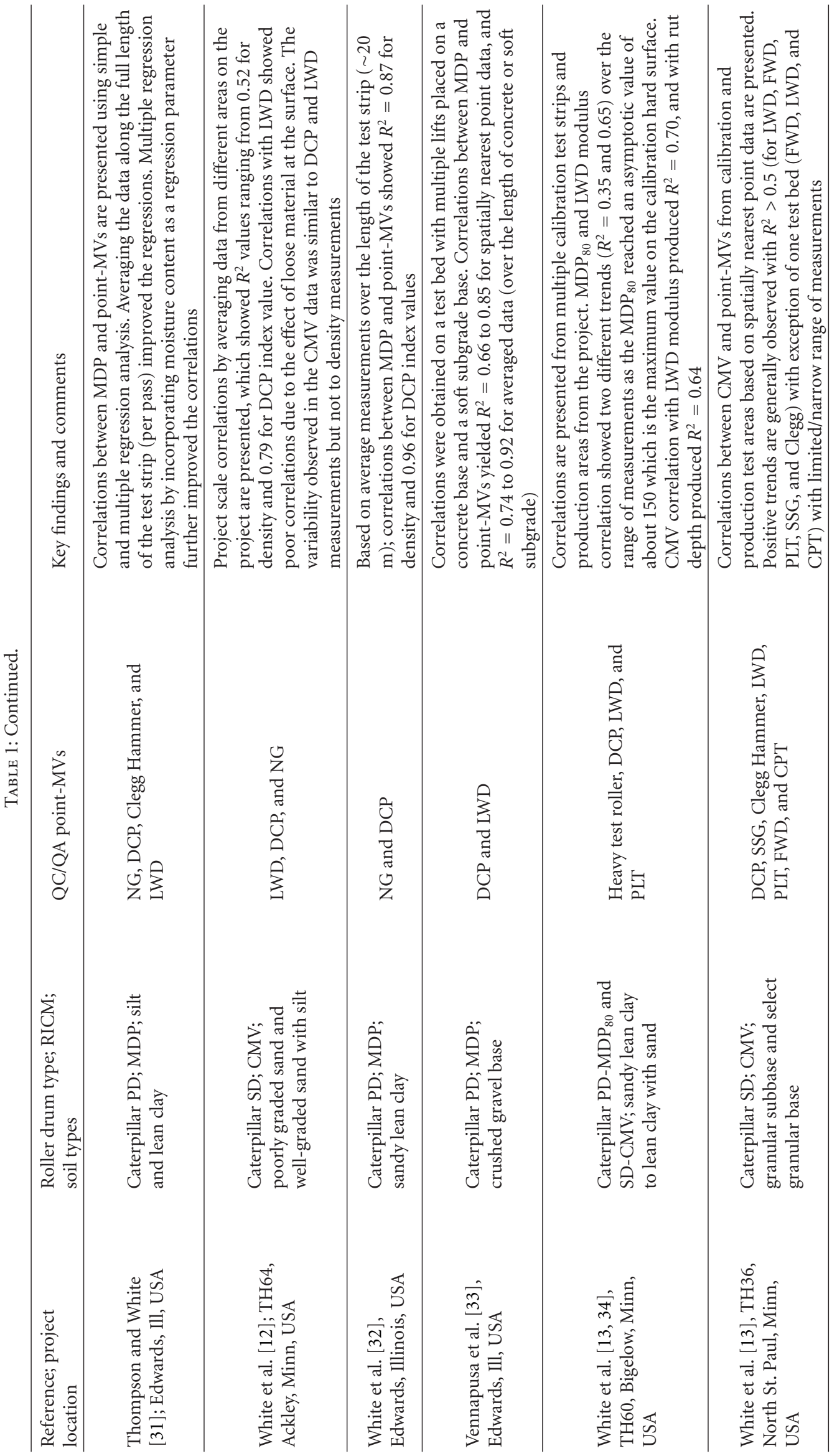




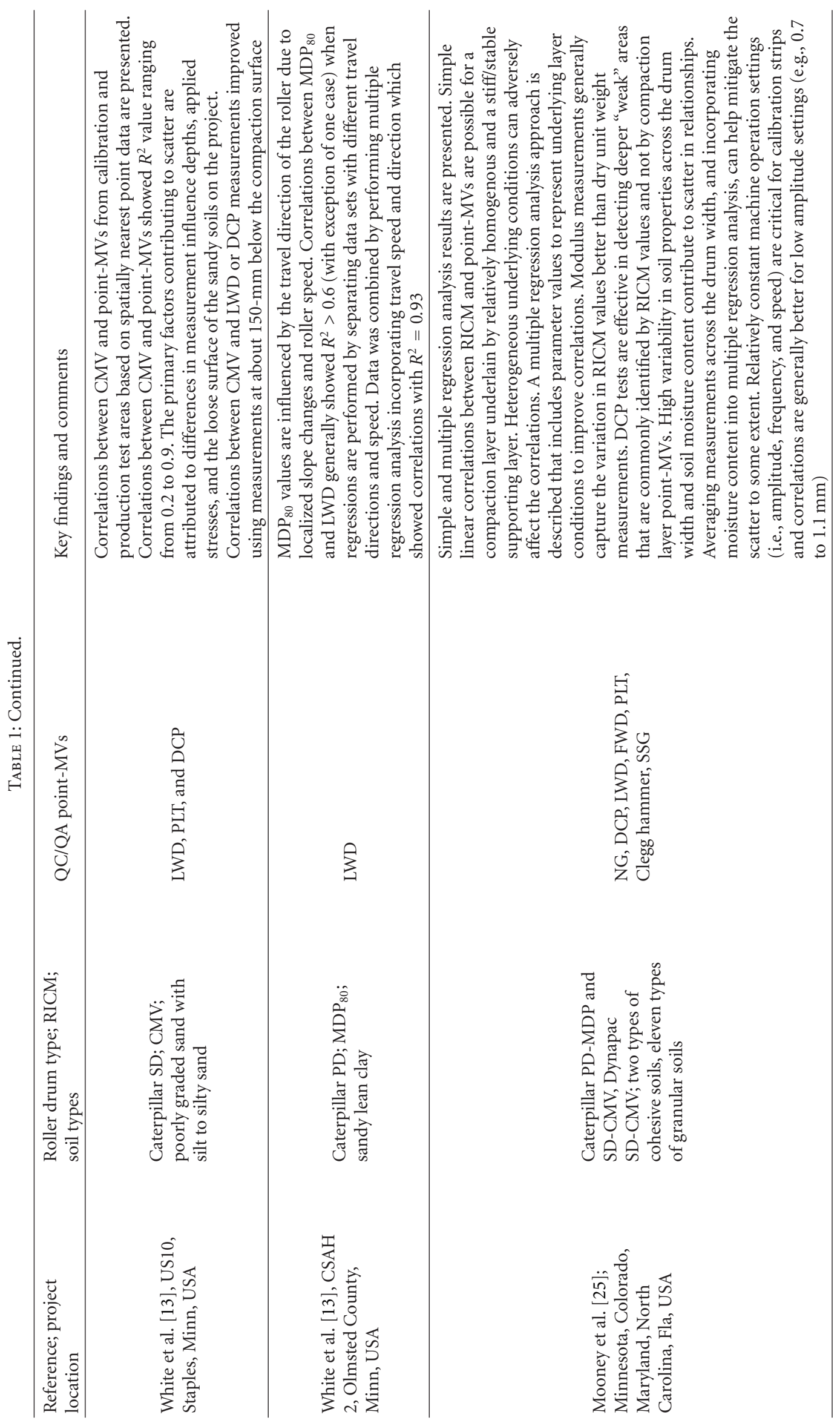




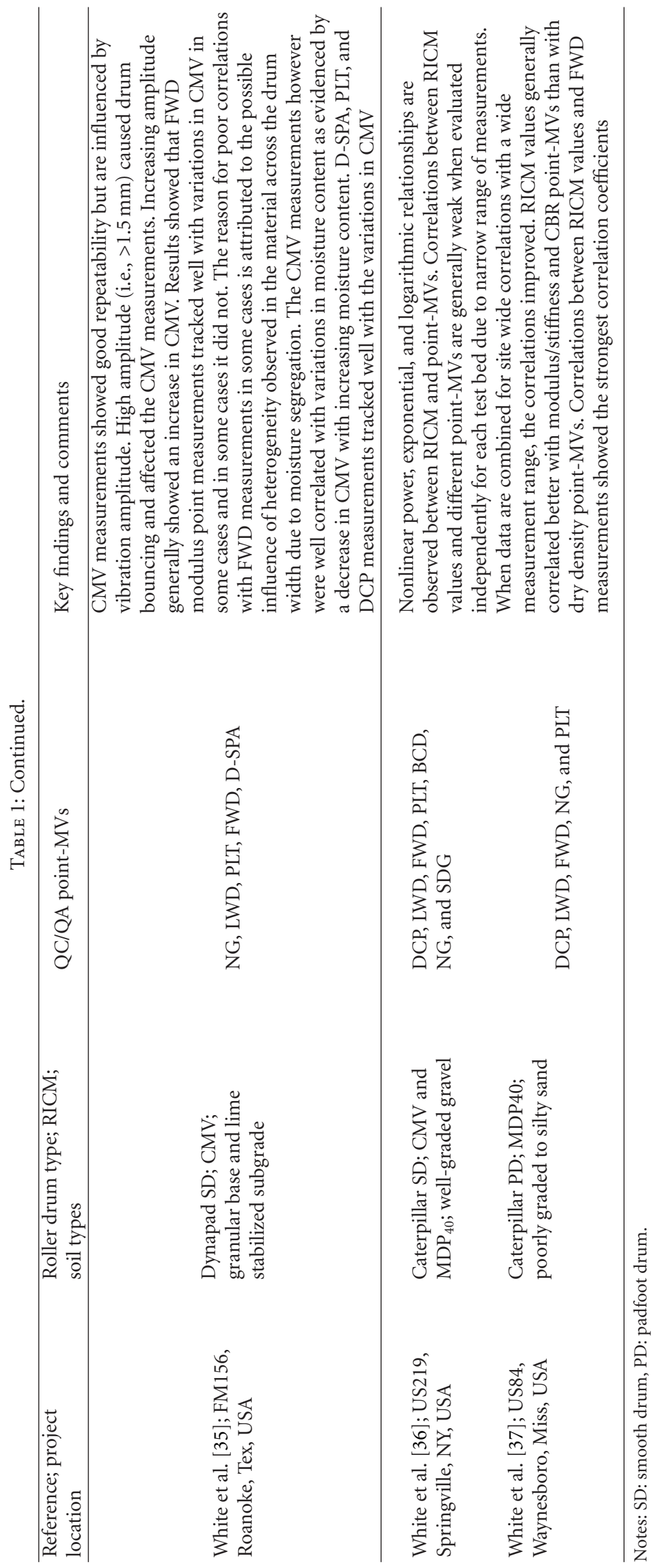




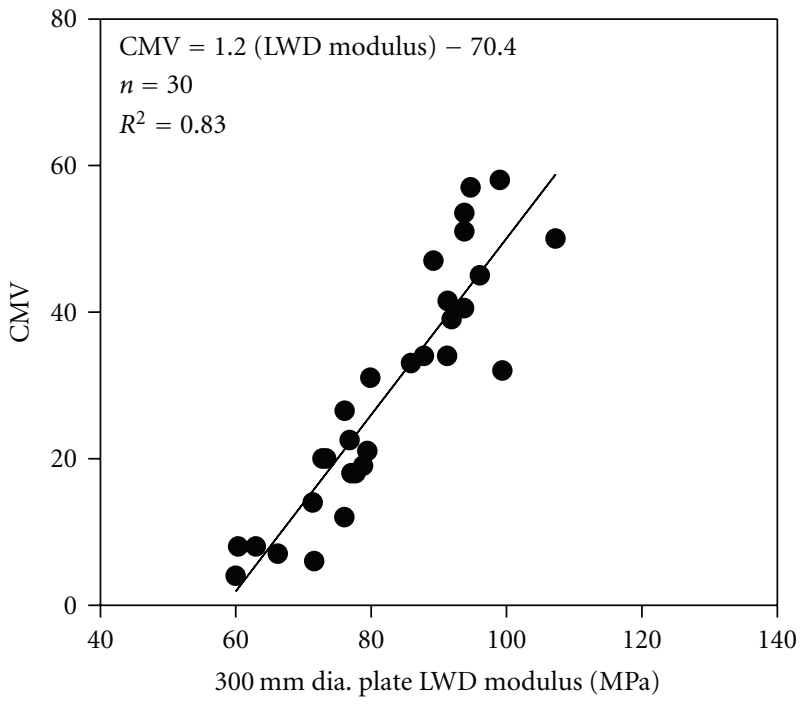

(a)

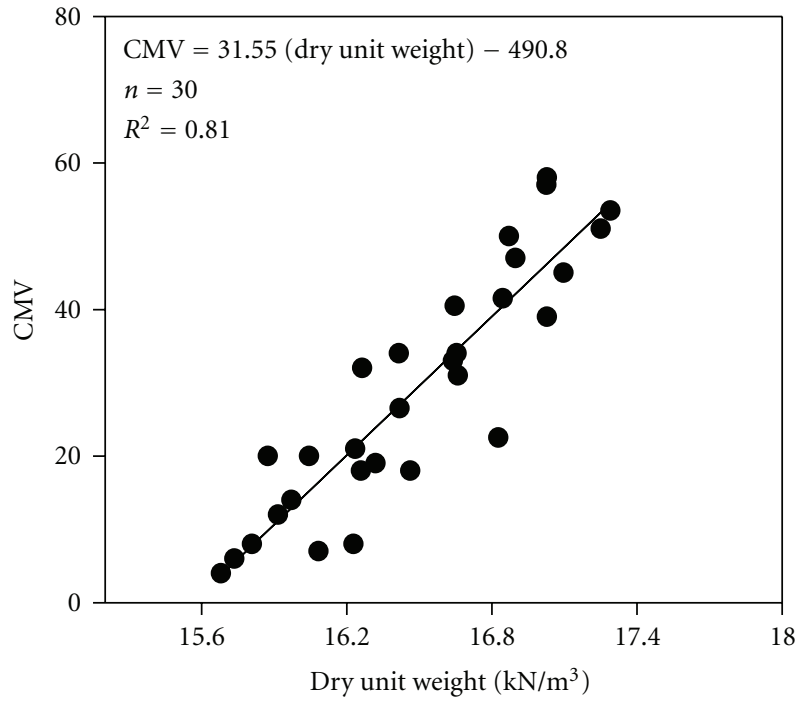

(b)

FIGURE 2: Simple linear regressions between CMV (amplitude $=1.00 \mathrm{~mm}$ ) and in situ point measurements (LWD modulus and dry unit weight)— silty sand with gravel underlain by fly ash stabilized subgrade.

RICM measurements and not by point-MVs obtained on the surface. This is primarily because of the differences in measurement influence depths. Accelerometer based roller measurements have measurement influence depths ranging from $0.8 \mathrm{~m}$ to $1.5 \mathrm{~m}$ depending on soil layering, drum mass, and excitation force $[25,39-41]$, while machine drive power based measurements range from 0.3 to $1.3 \mathrm{~m}$ depending on the heterogeneity in subsurface conditions [33]. On the other hand, most point-MVs have influence depths $<0.5 \mathrm{~m}$ [41]. Statistical multiple regression analysis techniques can be used to account for heterogeneity in the underlying layers if the underlying layer RICM or in situ point MV measurements have been demonstrated [25].

High variability in soil properties across the drum width and soil moisture content also contribute to scatter in relationships. Averaging point measurements across the drum width, and incorporating moisture content into multiple regression analysis, when statistically significant, can help mitigate the scatter to some extent. An example of multiple regression analysis by incorporating moisture content into the analysis is shown in Figure 5 based on the data described in Figure 4. Results indicate that the correlation between $\mathrm{MDP}_{40}$ and LWD modulus improved from $R^{2}$ value $=0.63$ to 0.71 , when moisture content is incorporated in to the regression analysis. $\mathrm{MDP}_{40}$ versus CBR dataset did not show much improvement when moisture content is incorporated, although it was found to be statistically significant (as assessed by $t$ and $P$ statistics).

\section{Spatial Analysis of In situ and RICM Measurements}

RICM technologies offer a unique advantage of quantifying and characterizing "nonuniformity" of compaction measurement values. This topic presumably should be of considerable interest to pavement engineers. Vennapusa et al. [22] demonstrated the use of variogram analysis in combination with conventional statistical analysis to effectively address the issue of nonuniformity in QC/QA during earthwork construction. A variogram is a plot of the average squared differences between data values as a function of separation or lag distance and is a common tool used in geostatistical studies to describe spatial variation. Three important features of a variogram include sill, range, and nugget. Sill is defined as the plateau that the variogram reaches, Range is defined as the distance at which the variogram reaches the sill, and Nugget is defined as the vertical height of the discontinuity at the origin which mostly represents sampling error or short scale variations [42]. From a variogram model, a low "sill" and longer "range of influence" can represent best conditions for uniformity, while the opposite represents an increasingly nonuniform condition.

To evaluate the application of spatial analysis, a test section was created for comparison analysis of CMV and MDP with DCP index values. The comparisons are shown using theoretical and experimental variogram models, and Kriged surface maps were generated for in situ compaction measurements using the theoretical (exponential) variogram model. The theoretical variograms were fit to the experimental variograms by checking for its "goodness" using the modified Cressie goodness of fit approach suggested by Clark and Harper [43]. A lower Cressie "goodness" factor indicates a better fit. The study area was comprised of a compacted subgrade material (Edwards glacial till material, USCS classification: CL) and a scarified portion (to a depth of $200 \mathrm{~mm}$ ) in a "Z" shape. The scarified portion was prepared intentionally to represent a common condition in earthwork construction resulting from utility trench 


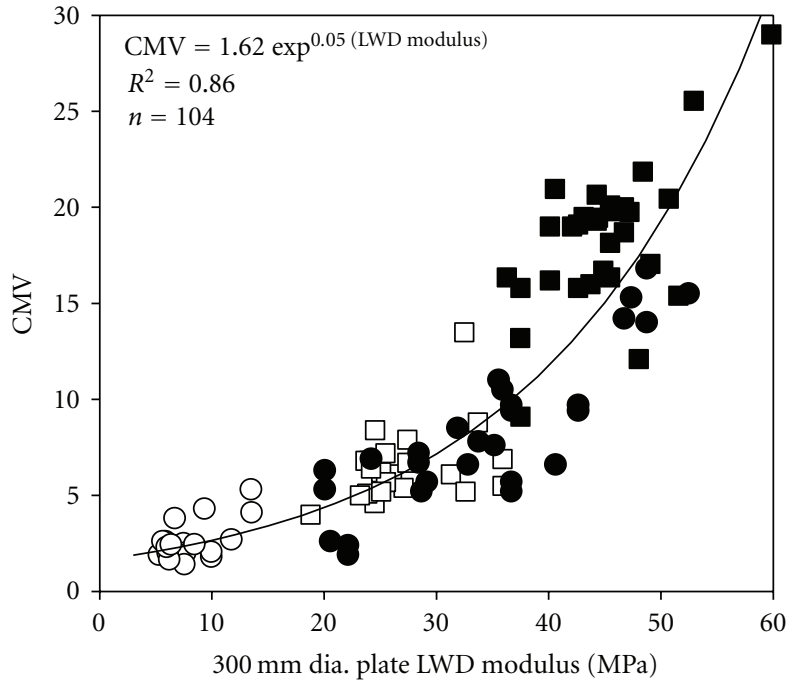

(a)

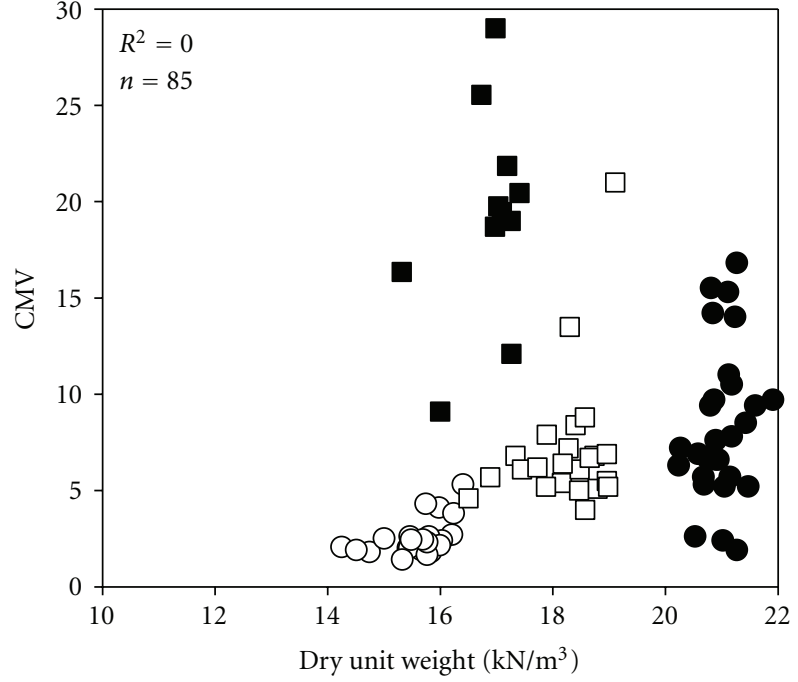

(b)

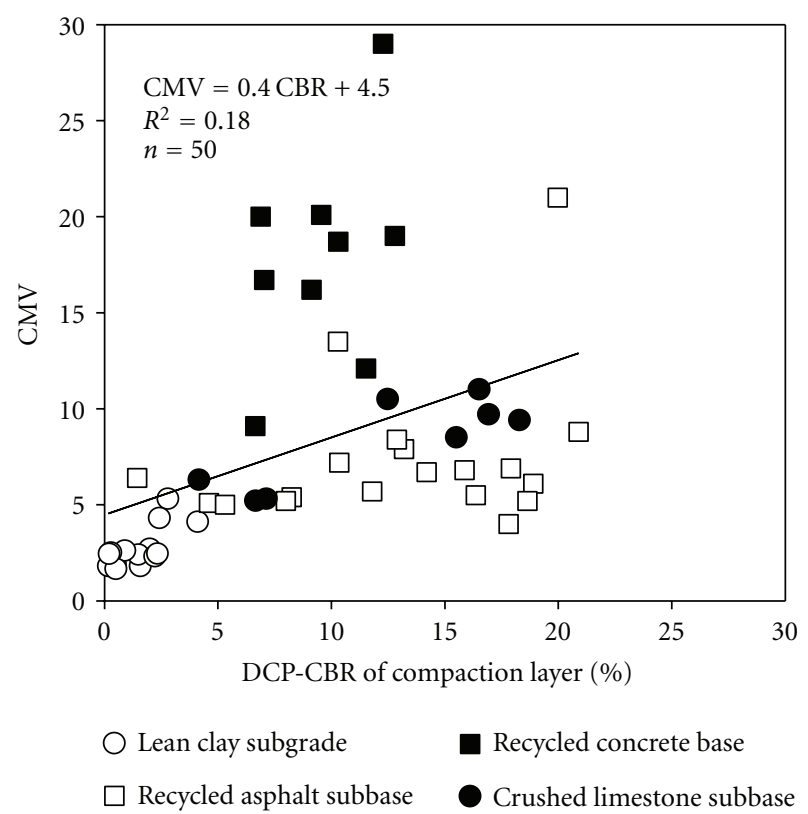

(c)

FIGURE 3: Relationships between CMV (theoretical amplitude $=1.50 \mathrm{~mm}$ ) and in situ point measurements (LWD modulus, dry unit weight, and CBR determined from DCP).

construction where the backfill may not be as compact as the neighboring unexcavated materials. After subgrade preparation, the area was mapped using a smooth drum machine in seven lanes using a vibration amplitude $=2.1 \mathrm{~mm}$ and frequency $=29 \mathrm{~Hz}$. DCP tests were performed at 144 locations in the upper $200 \mathrm{~mm}$ (shown in gray circles on Figure 6) following roller mapping passes. The DCP test locations were strategically spaced such that the boundaries of compacted and uncompacted areas were captured during Kriging interpolation.

CMV and MDP spatial data along with experimental and theoretical variogram models are shown in Figure 6. Log transformation of CMV was required to detrend the experimental variogram (details on detrending is explained in detail in Vennapusa et al. [22]). Kriged surface map and variogram model generated for the DCP index values are also presented in Figure 6. The univariate statistics (mean $(\mu)$, standard deviation $(\sigma)$, and coefficient of variation $(\mathrm{COV})$ ) of the measurement values are also provided on the figure for reference. The compacted and uncompacted areas were generally well captured by the CMV/MDP and DCP index measurements; however, they were more clearly delineated by the DCP Index measurements.

Univariate statistics show that the COV of the MDP (89\%) and DCP index (86\%) measurements are comparable and are also significantly higher compared to that of CMV (39\%). Similarly, the exponential variogram models of MDP and DCP index exhibit significantly lower range values than 


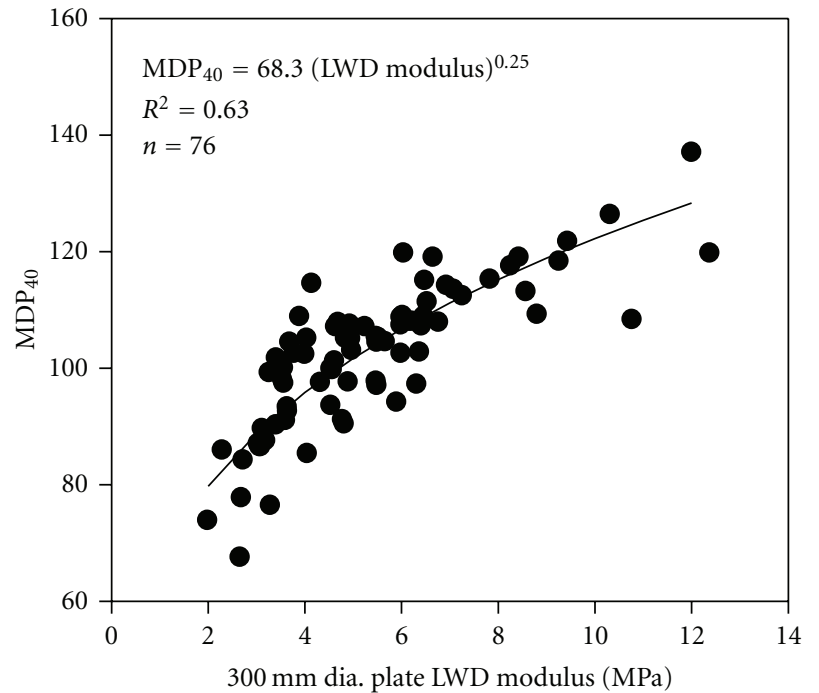

(a)

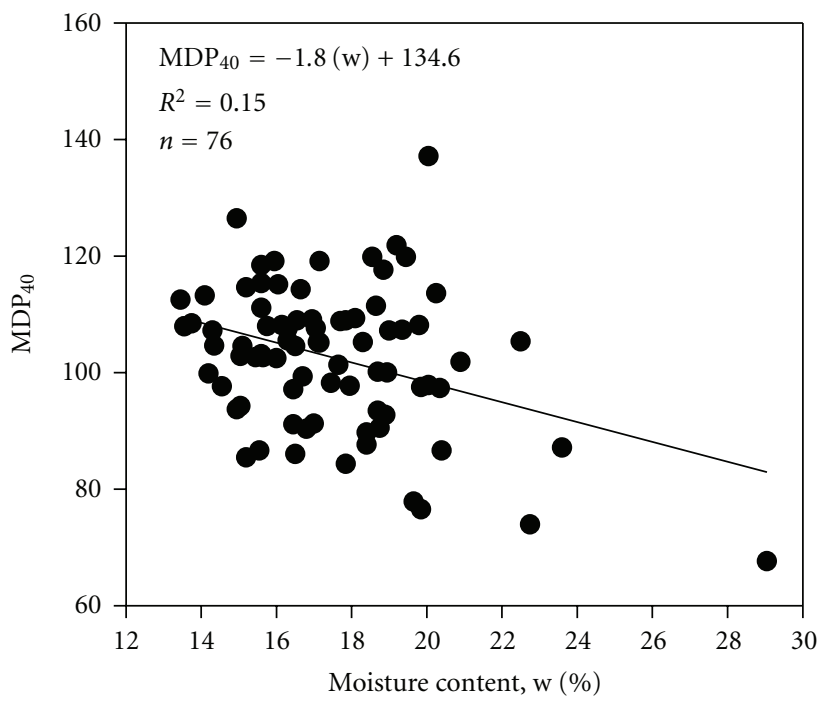

(c)

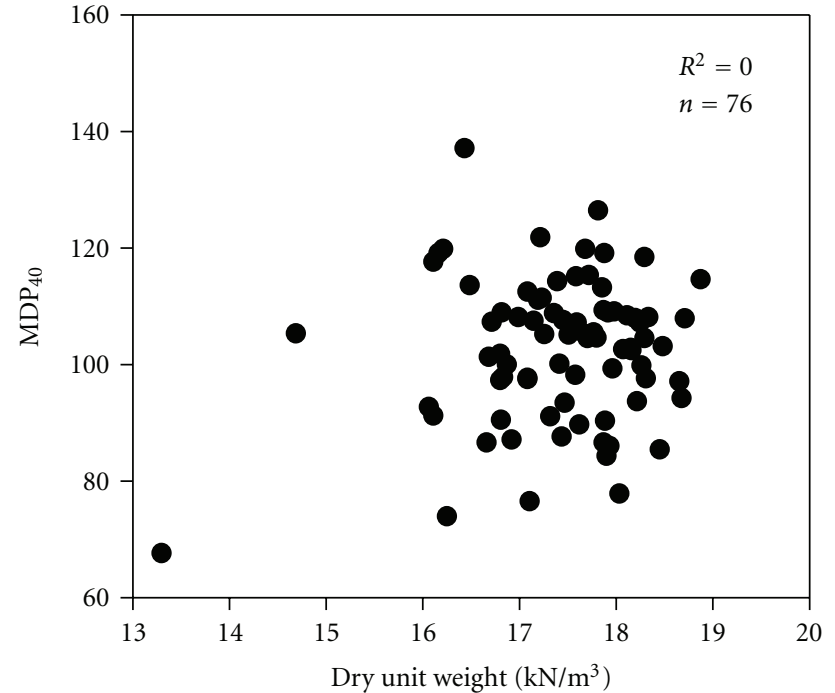

(b)

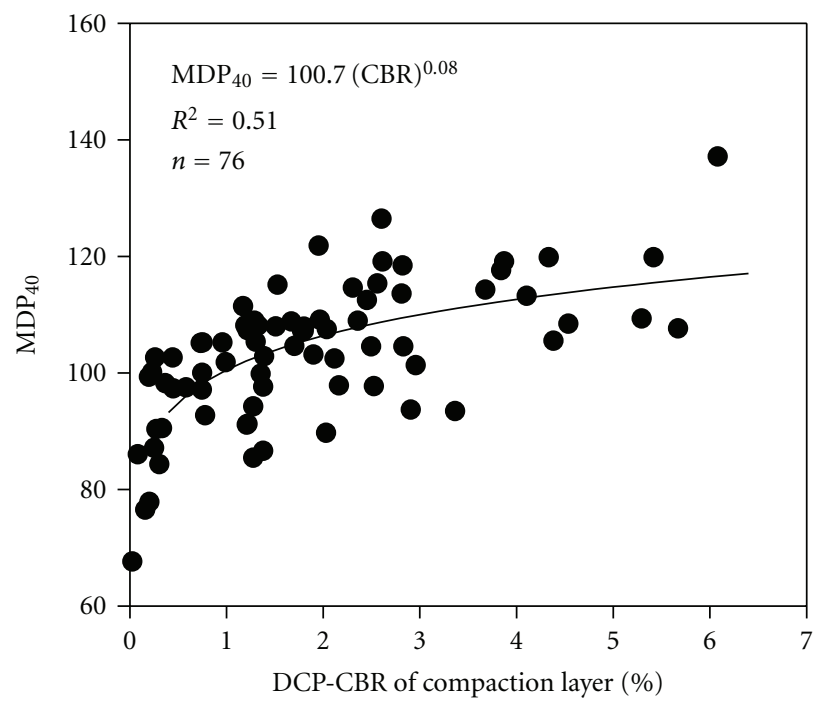

(d)

Figure 4: Example 3: Relationships between $\mathrm{MDP}_{40}$ (obtained in static mode) and in situ point measurements (LWD modulus, dry unit weight, moisture content, and CBR determined from DCP)—Sandy clay to silty clay subgrade.

CMV. This suggests that the MDP and DCP index measurements have less spatial continuity and higher variability compared to CMV measurements. This high variability is likely due to differences in the measurement influence depths of these measurements as discussed earlier in this paper. DCP index values presented in Figure 6 are based on average values in the top $300 \mathrm{~mm}$ of the surface.

In addition to using spatial analysis for visualization purposes, analysis from some field studies by the authors [36] has indicated that experimental semivariograms of RICM values sometimes show nested structures with distinctively different long- and short-range components. The nested structures are very likely linked to spatial variation in the underlying layer support conditions. These observations are new, have not been fully evaluated, and warrant more research. Further, a field study by White et al. [35] reported that variograms developed for two different spatial areas with similar univariate statistics (i.e., mean and standard deviation) showed distinctly different shapes of variograms with different spatial statistics, which illustrate the importance of spatial modeling to obtain better characterization of "nonuniformity" compared to using univariate statistics. This emphasizes the importance of dealing with "nonuniformity" in a spatial perspective rather than in a univariate statistics perspective.

\section{Implementation of RICM Technology}

A few countries and governmental agencies have developed specifications to facilitate implementation of RICM technologies into earthwork and hot mix asphalt (HMA) construction practices [44]. The international society of soil 


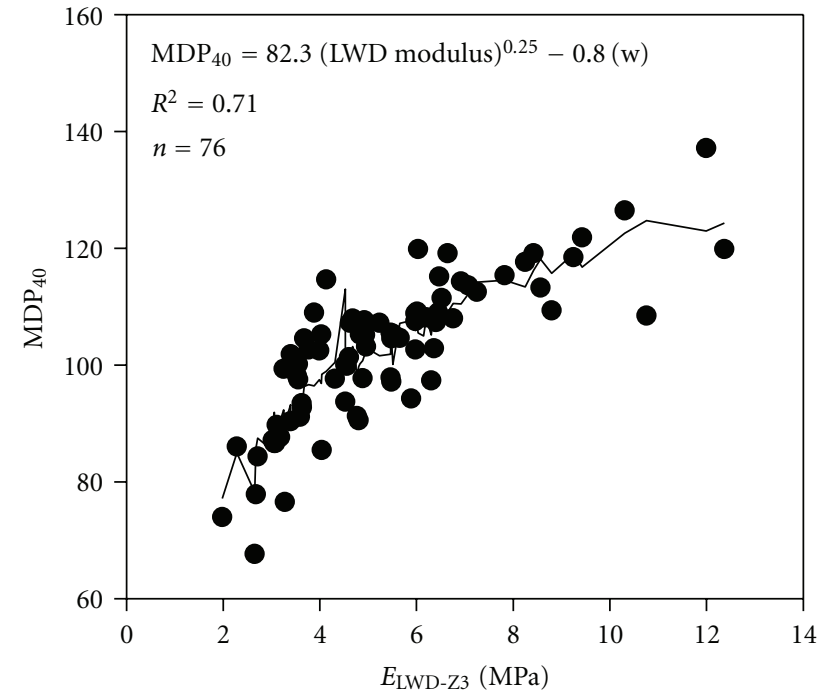

(a)

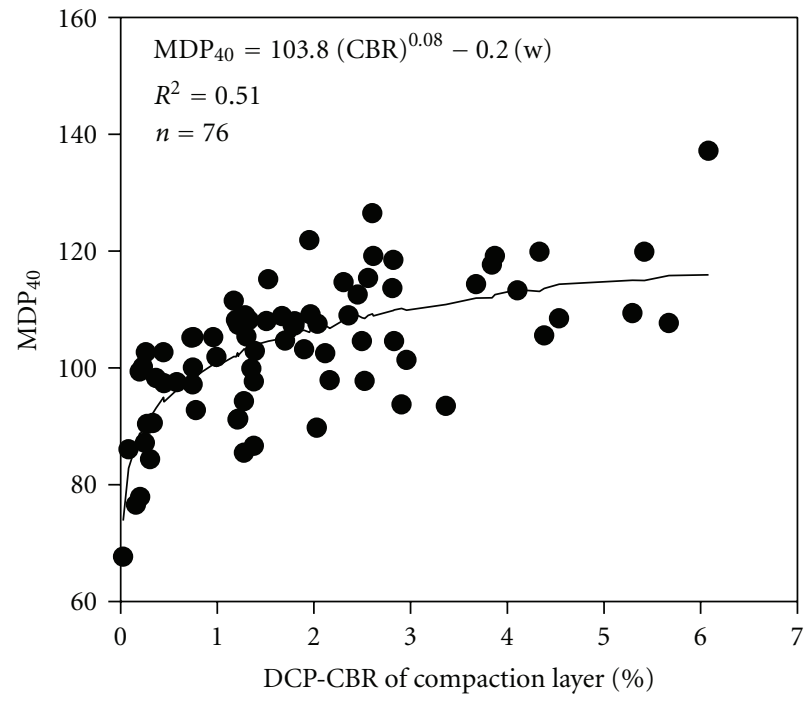

(b)

Figure 5: Example 4: Multivariate non-linear regression analysis between $\mathrm{MDP}_{40}$ and in situ point measurements (LWD modulus and CBR determined from DCP) using moisture content-Sandy clay to silty clay subgrade.

mechanics and geotechnical engineering (ISSMGE) [39], Minnesota department of transportation (DOT) [45, 46], Austrian [47], German [48], and Sweden [49] specifications require performing either static or dynamic plate load tests on calibration strips to determine average target values (typically based on 3 to 5 measurements) and use the same for QA in production areas. The ISSMGE, Austrian, and German specifications suggest performing at least three static plate load tests in locations of low, medium, and high degree of compaction during calibration process. Further, it is specified that linear regression relationships between roller compaction measurement values and plate load test results should achieve a regression coefficient, $R \geq 0.7$. Although it is not clear yet what the right number of test measurements is to develop a field calibration, the experience of the authors shows that by increasing the number of measurements to $10-15$ points, this substantially increases the statistical significance of the predictions.

One of the major limitations of the existing RICM specifications is that the acceptance requirements (i.e., percent target value limits, acceptable variability, etc.) are technology specific and somewhat based on local experience. This limitation hinders widespread acceptance of these specifications into practice as there are currently at least ten different RICM technologies. Significant efforts are being made in the US in developing widely acceptable and technology-independent specifications [3-5]. Based on feedback obtained from various state and federal agency personnel in recent national level workshops conducted on this topic, White and Vennapusa [4] documented the following as the key attributes of RICM specification:

(1) descriptions of the rollers and configurations,

(2) guidelines for operations (speed, vibration frequency and amplitude, and track overlap),
(3) records to be reported (time stamp, operations/ mode, soil type, moisture content, layer thickness, etc.),

(4) repeatability and reproducibility measurements for RICM values,

(5) ground conditions (smoothness, levelness, isolated soft/wet spots),

(6) calibration procedures for rollers and selection of calibration areas,

(7) regression analysis between RICM values and point measurements,

(8) number and location of quality control (QC) and quality assurance (QA) tests,

(9) operator training/certification, and

(10) acceptance procedures/corrective actions based on achievement of minimum RICM target values and associated variability.

Several new and innovative specification concepts have been proposed by researchers in the past few years $[4,13$, $25]$. These concepts primarily vary in the way the item number 10 listed above is dealt in the specification, that is, in the required level of upfront calibration work and data analysis which consequently leads to differences in the level of confidence in the quality of the completed work. A few of those concepts have been beta tested on demonstration level projects [25] but have never been fully evaluated on full scale projects to explore their limitations and advantages. More coordination between researchers and practitioners is needed to carefully evaluate these concepts and is a high-priority step forward to successfully implement the RICM technologies in practice. Further, integrating advanced analytical methods discussed in this 


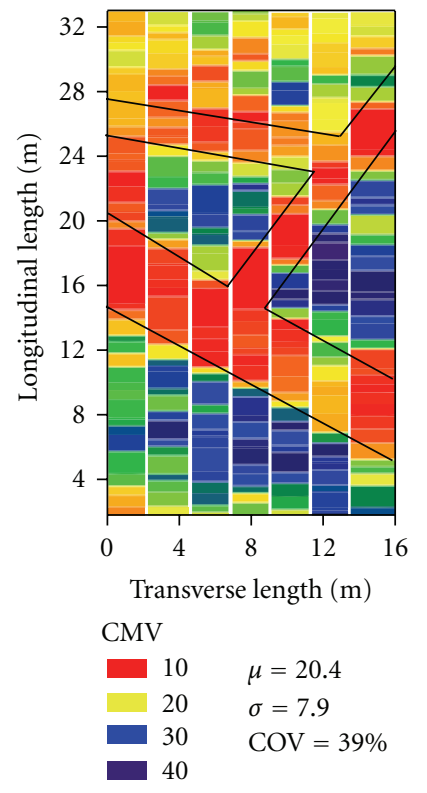

(a)

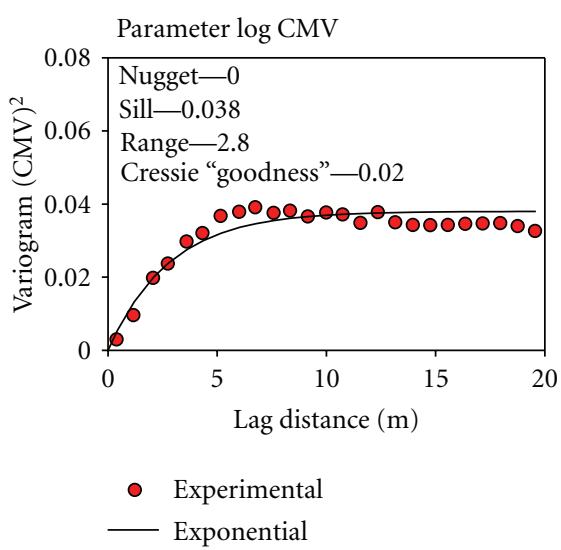

(d)

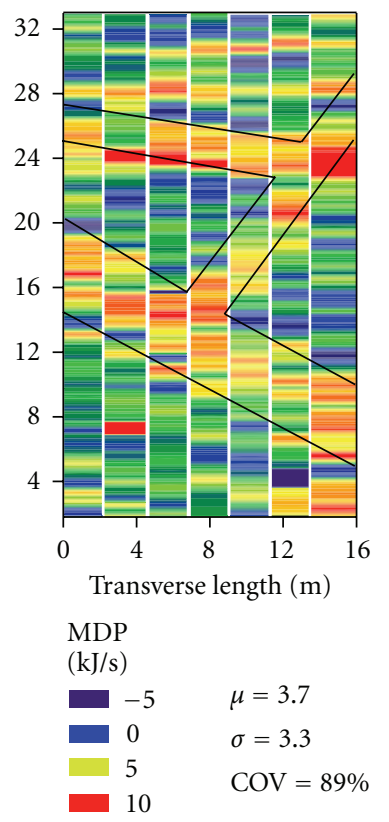

(b)

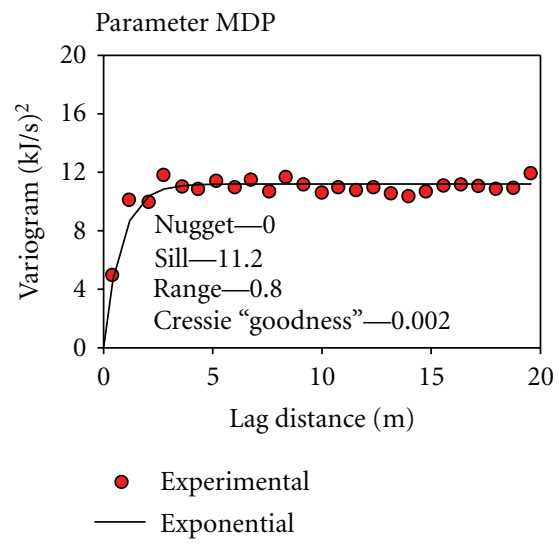

(e)

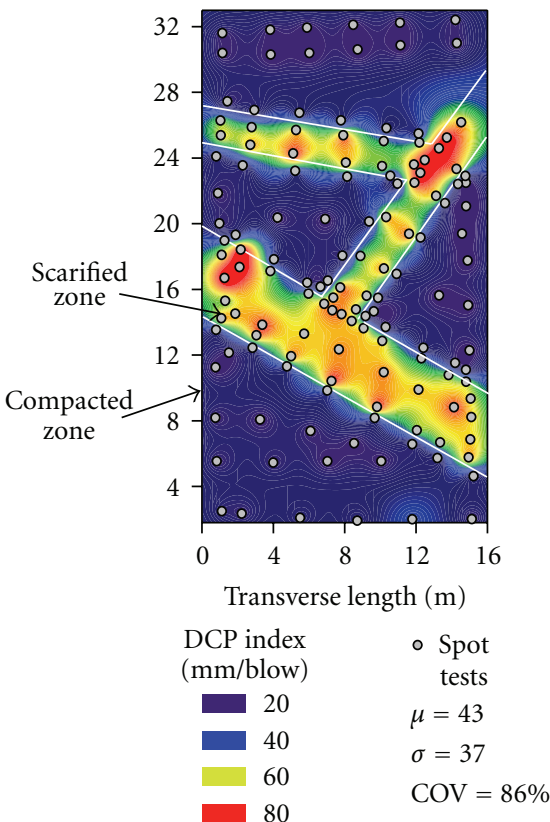

(c)

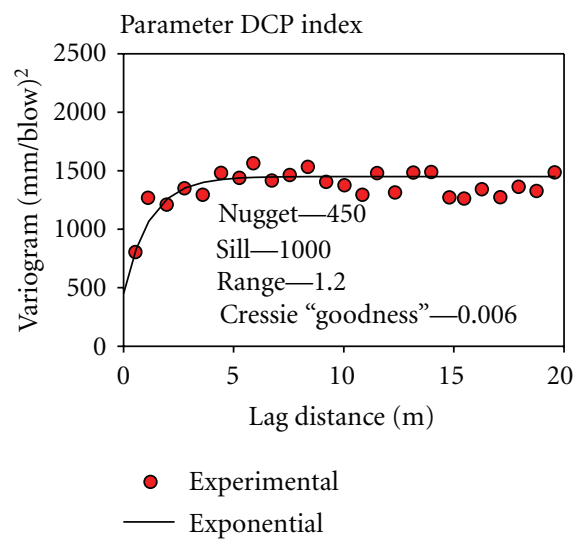

(f)

FIGURE 6: Spatial comparison of dynamic cone penetration (DCP) index and roller-integrated CMV and MDP measurements on compacted and scarified Edwards glacial till subgrade soil.

paper (such as simple and multiple regression analysis to develop correlations and target values and spatial analysis to address nonuniformity) into a specification along with development of simple and ready-to-use software tools is much necessary to help advance the technology.

\section{Concluding Remarks}

RICM technologies with real-time display capabilities and $100 \%$ coverage of compaction data offer significant advantages to the earthwork construction industry. Integration of these technologies into practice requires proper understanding of the correlations between RICM values and compaction measurements (e.g., density, modulus) and factors that influence these correlations. This paper provided an overview of two technologies (i.e., CMV and MDP) and a review of field correlation studies documented in the literature. Review of the literature revealed correlations between the RICM measurements and various in situ tests used to measure density, modulus or stiffness, shear strength, and CBR. Results from field studies indicated that simple linear or nonlinear correlations between any of these measurements are possible if the compaction layer is placed over a "stable" and "homogenous" underlying layer. If the underlying layer is not stable or homogenous, correlations are adversely affected. For those cases, in general, relationships between RICM and modulus based measurements (e.g., LWD or FWD or PLT modulus) are better compared to RICM and dry density or CBR measurements. Multiple regression analysis can be performed incorporating properties of the underlying layers and moisture content to improve correlations. Other important factors that affect the correlations include narrow 
range of measurements, variations in machine settings, nonuniform conditions across the drum width, limited number of measurements, and measurement error associated with both RICM and in situ point measurements.

Geostatistical spatial modeling techniques can be utilized for data visualization and characterization of spatial nonuniformity using spatially referenced RICM data. To demonstrate the application of spatial analysis for visualization, an example CMV and MDP data set over a spatial area was used in comparison with DCP index measurements. Analysis results indicated that the compacted and uncompacted areas over the spatial area were well captured by all the measurements. Some field studies documented in the literature indicate that geostatistical semivariograms of RICM measurements can be used for construction process control and also to analyze variations in the underlying support conditions. These observations are new, have not been fully evaluated, and warrant more research.

Review of current RICM specifications revealed a potential limitation with the acceptance requirements (i.e., percent target value limits, acceptable variability, etc.) being technology specific and somewhat based on local experience. This limitation hinders widespread acceptance of these specifications into practice as there are currently at least ten different RICM technologies. Several new specification concepts have been recently documented in the literature with variations in the way calibration work is performed and acceptance requirements are established. These concepts require detailed field evaluation to explore their limitations and advantages. Integration of advanced analytical methods discussed in this paper (such as simple and multiple regression analysis to develop correlations and target values, and spatial analysis to address nonuniformity) into a specification along with development of simple and ready-to-use software tools are much necessary to help advance the technology.

\section{Acknowledgments}

The results presented in this paper are from several research projects sponsored by the Highway Division of the Iowa Department of Transportation (DOT), Minnesota DOT, Federal Highway Administration, NCHRP, Caterpillar, Inc., and Iowa State University. The findings and opinions expressed in this paper are those of the authors and do not necessarily reflect the views of the sponsor and administrators. Several research associates, graduate, and undergraduate students at Iowa State University provided assistance with field testing.

\section{References}

[1] L. Forssblad, "Compaction meter on vibrating rollers for improved compaction control," in Proceedings of the International Conference on Compaction, vol. 2, pp. 541-546, Paris, France, 1980.

[2] H. Thurner and A. Sandström, "A new device for instant compaction control," in Proceedings of the International Conference on Compaction, vol. 2, pp. 611-614, Paris, France, 1980.
[3] D. J. White, "Workshop on intelligent compaction for soils and HMA," Report ER08-01, Iowa State University, Ames, Iowa, USA, 2008.

[4] D. J. White and P. Vennapusa, "Report of the workshop on intelligent technologies for earthworks," in Proceedings of the 2nd Annual Workshop, no. ER09-02, Iowa DOT and the Earthworks Engineering Research Center at Iowa State University, Sheraton West Des Moines Hotel, West Des Moines, Iowa, USA, April 2009.

[5] D. J. White and P. Vennapusa, "Report of the webinar workshop on intelligent compaction for earthworks and HMA," in Proceedings of the 3rd Annual Workshop, no. ER1002, Earthworks Engineering Research Center at Iowa State University and the Iowa DOT, Ames, Iowa, USA, March 2010.

[6] H. Brandl and D. Adam, "Sophisticated continuous compaction control of soils and granular materials," in Proceedings of the 14th International Conference on Soil Mechanics \& Foundation Engineering, vol. 1, Hamburg, Germany, September 1997.

[7] M. A. Mooney and D. Adam, "Vibratory roller integrated measurement of earthwork compaction: an overview," in Proceedings of the 7th International Symposium on Field Measurements in Geomechanics (FMGM '07), ASCE, Boston, Mass, USA, 2007.

[8] A. Sandström and C. Pettersson, "Intelligent systems for QA/ QC in soil compaction," in Proceedings of the Annual Transportation Research Board Meeting, Washington, DC, USA, January 2004.

[9] D. J. White, E. J. Jaselskis, V. R. Schaefer, and E. T. Cackler, "Real-time compaction monitoring in cohesive soils from machine response," Transportation Research Record, no. 1936, pp. 173-180, 2005.

[10] R. Sullivan, R. Anderson, Biesiadecki, T. Bond, and H. Stewart, "Martian regolith cohesions and angles of internal friction from analysis of MER wheel trenches," in Proceedings of the 38th Lunar and Planetary Science Conference, League City, Tex, USA, March 2007.

[11] D. J. White, M. Morris, and M. Thompson, "Power-based compaction monitoring using vibratory padfoot," in Proceedings of the Geotechnical Engineering in the Information Technology Age (GeoCongress '06), p. 44, Atlanta, Ga, USA, March 2006, CD-ROM.

[12] D. J. White, M. Thompson, P. Vennapusa, and J. Siekmier, "Implementing intelligent compaction specifications on Minnesota TH 64: synopsis of measurement values, data management, and geostatistical analysis," in Proceedings of the Annual Transportation Research Board Meeting, Washington, DC, USA, January 2008.

[13] D. J. White, P. Vennapusa, J. Zhang, H. Gieselman, and M. Morris, "Implementation of intelligent compaction performance based specifications in Minnesota," Report ER09-03, MN/RC 2009-14, Minnesota Department of Transportation, St. Paul, Minn, USA, 2009.

[14] Iowa DOT, "Special provisions for intelligent compactionHMA SP-090048(New)," Harrison County NHSN-0301(127)—2R-43, Iowa DOT, Ames, Iowa, USA, 2010.

[15] Iowa DOT, "Special provisions for intelligent compactionHMA SP-090057a," Ida County NHSN-020-2(70)—2R-47, Iowa DOT, Ames, Iowa, USA, 2010.

[16] Iowa DOT, "Special provisions for intelligent compactionHMA roller pass mapping SP-090058 (New)," Kossuth County STPN-009-4(44)—2J-55, Iowa DOT, Ames, Iowa, USA, 2010. 
[17] Iowa DOT, "Special provisions for intelligent compactionEmbankment SP-090063 (New)," Sac County NHSX-0202(89)—3H-81, Iowa DOT, Ames, Iowa, USA, 2010.

[18] J. Siekmeier and M. Oman, "Intelligent compaction to determine highway subcut depth during construction. Presented in the workshop on reinventing geotechnical investigations," in Proceedings of the 90th Annual Transportation Research Board Meeting, Washington, DC, USA, January 2011.

[19] Å. Sandström, "Numerical simulation of a vibratory roller on cohesionless soil," Internal Report, Geodynamik, Stockholm, Sweden, 1994.

[20] S. Hansbo and B. Pramborg, "Compaction control," in Proceedings of the International conference on Compaction, vol. 2, pp. 559-564, Paris, France, 1980.

[21] Geodynamik ALFA-030. Compactometer, Compaction Meter for Vibratory Rollers, ALFA-030-051E/0203, Geodynamik AB, Stockholm, Sweden.

[22] P. K. R. Vennapusa, D. J. White, and M. D. Morris, "Geostatistical analysis for spatially referenced roller-integrated compaction measurements," Journal of Geotechnical and Geoenvironmental Engineering, vol. 136, no. 6, pp. 813-822, 2010.

[23] M. Bekker, Introduction to Terrain-Vehicle Systems, The University of Michigan Press, Ann Arbor, Mich, USA, 1969.

[24] F. Peyret, D. Bétaille, and G. Hintzy, "High-precision application of GPS in the field of real-time equipment positioning," Automation in Construction, vol. 9, no. 3, pp. 299-314, 2000.

[25] M. Mooney, R. Rinehart, D. J. White, P. Vennapusa, N. Facas, and O. Musimbi, "Intelligent soil compaction systems," Final Report NCHRP 21-09, National Cooperative Highway Research Program, Washington, DC, USA, 2010.

[26] R. Floss, N. Gruber, and J. Obermayer, "A dynamical test method for continuous compaction control," in Proceedings of the 8th European Conference on Soil Mechanics and Foundation Engineering, H. G. Rathmayer and K. H. O. Saari, Eds., pp. 2530, Helsinki, Finland, May 1983.

[27] Y. Nohse, K. Uchiyama, Y. Kanamori et al., "An attempt applying a new control system for the vibratory compaction using GPS and CMV in the embankment construction (Part 1)," in Proceedings of the 13th International Conference of the ISTVS, pp. 295-300, Okinowa, Japan, 1999.

[28] D. J. White, E. Jaselskis, V. Schaefer, T. Cackler, I. Drew, and L. Li, "Field evaluation of compaction monitoring technology: phase I," Final Report, Iowa DOT Project TR-495, Iowa State University, Ames, Iowa, USA, 2004.

[29] L. Petersen and R. Peterson, "Intelligent compaction and InSitu testing at Mn/DOT TH53," Final Report MN/RC-200613, Minnesota DOT, St. Paul, Minn, USA, 2006.

[30] D. J. White, M. Thompson, K. Jovaag et al., "Field evaluation of compaction monitoring technology: phase II," Final Report, Iowa DOT Project TR-495, Ames, Iowa, USA, 2006.

[31] M. J. Thompson and D. J. White, "Estimating compaction of cohesive soils from machine drive power," Journal of Geotechnical and Geoenvironmental Engineering, vol. 134, no. 12, pp. 1771-1777, 2008.

[32] D. J. White, M. Thompson, and P. Vennapusa, Field Study of Compaction Monitoring Systems-Tamping Foot 825 and Vibratory Smooth Drum CS-533E Rollers, Center of Transportation Research and Education, Iowa State University, Ames, Iowa, USA, 2007.

[33] P. Vennapusa, D. J. White, and H. Gieselman, "Influence of support conditions on roller-integrated machine drive power measurements for granular base," in Proceedings of the International Foundation Congress and Equipment Expo (IFCEE '09), Orlando, Fla, USA, March 2009.

[34] D. J. White, P. Vennapusa, H. Gieselman, L. Johanson, and J. Siekmeier, "Alternatives to heavy test rolling for cohesive subgrade assessment," in Proceedings of the 8th International Conference on the Bearing Capacity of Roads, Railways, and Airfields (BCR2A '09), Champaign, Ill, USA, June 2009.

[35] D. J. White, P. Vennapusa, H. Gieselman, L. Johanson, and R. Goldsmith, "Accelerated implementation of intelligent compaction monitoring technology for embankment subgrade soils, aggregate base, and asphalt pavement materials TPF5(128) - Texas IC demonstration field project," Report, The Transtec Group, FHWA, 2008.

[36] D. J. White, P. Vennapusa, H. Gieselman et al., "Accelerated implementation of intelligent compaction monitoring technology for embankment subgrade soils, aggregate base, and asphalt pavement materials TPF-5(128)—New York IC demonstration field project," Report ER10-01, The Transtec Group, FHWA, 2010.

[37] D. J. White, P. Vennapusa, H. Gieselman, B. Fleming, S. Quist, and L. Johanson, "Accelerated implementation of intelligent compaction monitoring technology for embankment subgrade soils, aggregate base, and asphalt pavement materials TPF-5(128)—Mississippi IC demonstration field project," Report ER10-03, The Transtec Group, FHWA, 2010.

[38] ASTM D6951-03, Standard Test Method for Use of the Dynamic Cone Penetrometer in Shallow Pavement Applications, American Standards for Testing Methods, West Conshohocken, Pa, USA.

[39] ISSMGE, Roller-Integrated Continuous Compaction Control (CCC): Technical Contractual Provisions, Recommendations, TC3: Geotechnics for Pavements in Transportation Infrastructure, International Society for Soil Mechanics and Geotechnical Engineering, 2005.

[40] R. V. Rinehart and M. A. Mooney, "Measurement depth of vibratory roller-measured soil stiffness," Géotechnique, vol. 59, no. 7, pp. 609-619, 2009.

[41] P. Vennapusa, D. J. White, J. Siekmeier, and R. Embacher, "In situ mechanistic characterizationsof granular pavement foundation layers," International Journal of Pavement Engineering. In press.

[42] R. M. Srivastava, "Describing spatial variability using geostatistical analysis," in Geostatistics for Environmental and Geotechnical Applications, R. M. Srivastava, S. Rouhani, M. V. Cromer, A. J. Desbarats, and A. I. Johnson, Eds., vol. 1283, ASTM, West Conshohocken, Pa, USA, 1996.

[43] I. Clark and W. Harper, Practical Geostatistics 2000, Ecosse North America Llc, Columbus, Ohio, USA, 3rd edition, 2002.

[44] D. J. White, M. Thompson, and P. Vennapusa, "Field validation of intelligent compaction monitoring technology for unbound materials," Final Report MN/RC-2007-10, Minnesota DOT, St. Paul, Minn, USA, 2007.

[45] Mn/DOT, Excavation and Embankment-(QC/QA) IC Quality Compaction (2105) Pilot specification for Granular Treatment S.P.0301-47, Minnesota DOT, St. Paul, Minn, USA, 2007.

[46] Mn/DOT, Excavation and Embankment-(QC/QA) IC Quality Compaction (2105) Pilot Specification for Non-Granular Soils S.P.6211-81, Minnesota DOT, St. Paul, Minn, USA, 2007.

[47] RVS 8S.02.6, "Continuous compactor integrated compaction-proof (proof of compaction)," Technical Contract Stipulations RVS 8S.02.6-Earthworks, Federal Ministry for Economic Affairs, Vienna, Austria, 1999. 
[48] ZTVE StB/TP BF-StB, "Surface Covering Dynamic Compaction Control Methods-German Specifications and Regulations," Additional Technical Contractual Conditions and Guidelines for Earthwork in Road Construction and Technical Testing Instructions for Soil and Rock in Road Construction, Research Society of Road and Traffic, Germany, 1994.

[49] ATB Väg, "Kapitel E-Obundna material VV Publikation 2005:112," General technical construction specification for roads, Road and Traffic Division, Sweden, 2005. 

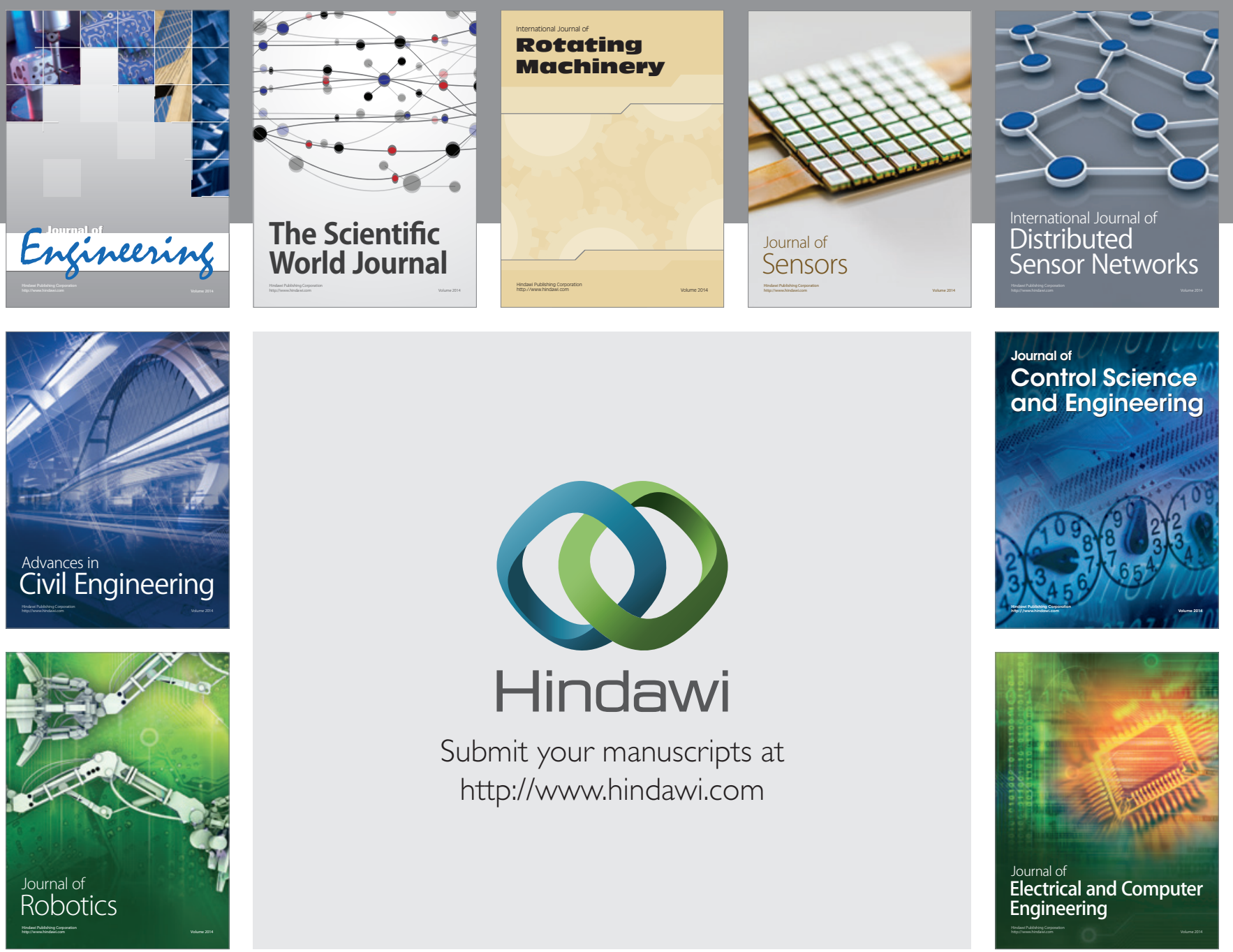

Submit your manuscripts at

http://www.hindawi.com
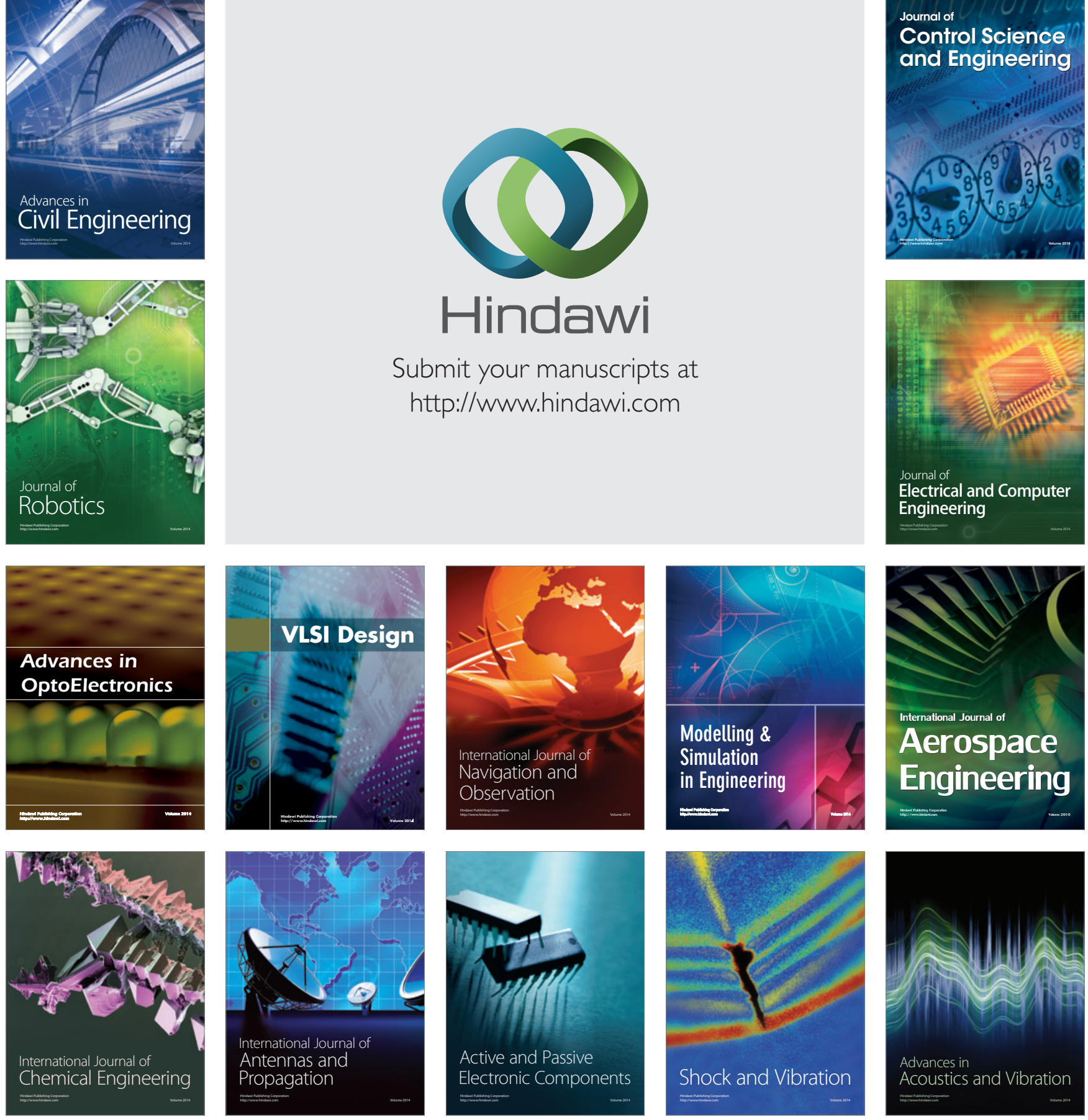